\title{
Tour and Travel Website Beliefs in Influencing Users Satisfaction - Case Study: Malaysia
}

\author{
Puteri Fatin Nadia and Vera Pujani
}

\begin{abstract}
This research framework was developed based on theory planned behavior. This study is to examine the influences the enjoyment, self-efficacy and actual use towards the users satisfaction of e-travel website in Malaysia". From a multistage data sampling among Malaysian customer of e-travel, a total of 105 questionnaires were returned and analyzed. The data was analyzed using SmartPLS and SPSS 16. The results revealed significant influences of enjoyment, self-efficacy and the actual use of web site on the users satisfaction of e-travel website. All variables moderated positively to the influence of customer satisfaction. The paper highlights its influence of each variables.
\end{abstract}

Index Terms-Tourism, e-travel, satisfaction, enjoyment.

\section{INTRODUCTION}

JARING is the first Malaysian internet service provider (ISP) back in 1990 and later TM Net in 1995 [1]. Starting then, the growth of Internet usage in Malaysia keep increasing each year. In this acceleration of technology advancement era, the emergence of information and communication technologies (ICT) contribute to the escalation of tourism industry to be the major evolving industry in Malaysia. As ICT is the electronic tools that facilitate the operational of the organization along as facilitate the industry by reducing the costs of distributing and promoting their products and services [2].

The tremendous changes that was brought by the Internet, has be penetrated in every corner of the world including communication, education, and finance to entertainment, as it can clearly be the application of the Internet. Besides, the Internet has resulted in a great revolution for every industry especially in the tourism industry for the e-travel website.

The emergence of tourism website facilitate the $16,902,600$ Internet user in Malaysia (internet world stats, 2009) in online activities related to the industry such as information gathering, airline reservation, hotel booking and as the primary source of reference, event tickets and packaged tours. This development and growth imply that businesses and customers perceive that the Internet provides them with some kind of value [3]. Besides that, by using the Internet in the planning of a holiday, it contributes to a greater

Manuscript received May 20, 2014; revised July 22, 2014. This work was supported Minister of Indonesian Higher Education (Dikti-DP2M) and University of Andalas, Indonesia (financial support of this research as International Research Collaboration grant and scientific Publication. Full names of authors are preferred in the author field, but are not required. Put a space between authors' initials.

Puteri Fatin Nadia is with University of Andalas. Limau Manih, Padang, Indonesia, 25165 (e-mail: puterifatin18@yahoo.com).

Vera Pujani is with Andalas University, Limau Manih Padang, Indonesia 25162 (e-mail: verapujani@yahoo.co.id). enjoyment of the holiday irrespective of previous attitude towards the destination as the travel agent website has provide various information details that customer need in order to make preparation. Hence, e-travel can promote their product such as ticket by also providing information about tourism and beautiful places in Malaysia when it has become their holiday destination.

According to Lexhagen, travel and tourism website is one of top visited websites by internet users [4]. As this is because travel and tourism websites is visited to search information or to buy travel and tourism products such as packaged tours, airplane tickets, accommodation and etc [4]. Using internet to find information and planning for a holiday will contributes to an enjoyment of holiday on not taking any risk towards destination [2]. As internet has become the medium in promoting and marketing the travel agent products and services as it has increase the possibility for any services and products providers to engage in direct marketing once a potential customer has entered the travel agent official or non official website. This has makes internet become the most famous system where everyone uses this system to make their life easier and faster.

Then, e-commerce is a very useful system to expand marketplace. The emergence of information and technology contributed to the rapid growth of electronic market place [5].

As enjoyment do reflects to the consumer perception regarding the potential entertainment of the Internet shopping. According to Davis, introduced Technology Acceptance Model (TAM) that has a good in both explaining and predicting intention of use and behavior of acceptance as an instrument to predict the likelihood of a new technology that being adopted within a group or an organization [6]. By the preceding consideratons, the following research questions are proposed:

How the factors of enjoyment, actual use of website and self-efficacy gives influence towards the satisfaction of users that using e-travel website?

This paper organized as follows. Starting from the beginning is the review of Theory Planned Behavior, satisfaction, then actual use, continue with self-efficacy and the last one is enjoyment. The research hypothesis are proposed and continued by research method and then results to answer the research questions. In the last section, the conclusion and implication are discussed.

\section{LITERATURE REVIEW}

\section{A. Theory Planned Behavior}

Theory Planned Behavior explains about human behavior that says behavioral intention is the direct antecedents of actual use behavior. Thus, the theory of planned behavior is a 
theory that predicts deliberate behavior, because behavior can be deliberative and planned [7].

There are three functions conceptual of behavioral intention [7]: attitude defined evaluation of behavior, subjective norms defined as person who is estimated the social pressure to perform certain behavior, and perceived behavioral control defined the extension of someone's feeling either they are able to enact behavior.

\section{B. Satisfaction}

Satisfaction is defines as the degree to which a business's product or service performance matches up to the expectation of the customer then if the performances matches with customer expectation, the customer is satisfied [8]. For users satisfaction it is an important predictor of online consumer behavior and the success of a web-based system [9]. It also a common measurement for success of information system or any several standardized instruments that have been developed and tested [10].

Satisfaction is also a customer emotional responses when he or she evaluating the discrepancy between expectation of service and perception of actual performance [8]. The perception of performance is gained through physical interaction with the business, product and services of the business [11].

Here, the more satisfied a customers of users with the e-travel website, they will tend to repeat purchase, brand loyalty, and positive word of mouth marketing. Customer satisfaction leads to repeat purchases, loyalty and to customer retention [6]. According to Kotler, it defined satisfaction as a person's feelings of pleasure or disappointment resulting from comparing a product perceived performance or outcome in relation to the customer expectations [12]. Other than that, on the other hand of dissatisfied customers that respond differently. Dissatisfied customers might try to reduce the dissonance by abandoning or returning the product or services, or complaining about the product or services, and they may try to reduce the dissonance by seeking information that might confirm its high value [12].

Thus, satisfaction also a combination of two responses such as cognitive and affective response to service encounters while, service quality is the overall assessment of a firm's service delivery system. By that, service quality is the delivery of services while satisfaction is customers' experiences with services. Though, it emphasize the importance of e-commerce users satisfaction and it defines as the reaction or feeling of a customer in relation to his/her experience with all aspects of an e-commerce system [13].

\section{Enjoyment}

Enjoyment is as physical, social, and cognitive spontaneity, manifest joy, and sense of humor. This emphasizes that enjoyment is concerned with the individual's perception of how much fun he or she is having when undertaking an activity and a sense of humor. Enjoyment can also refer to the extent to which the activity of using a computer system is perceived to be personally enjoyable in its own right aside from the instrumental value of the technology [7]. On the other hand, enjoyment is the feelings people experience when they break through the limits of homeostasis especially when they do something that stretches them beyond what they were. Rather than pleasure, enjoyment also leads to personal growth and long term happiness [14].

Thus, enjoyment also categorized as intrinsic motivation that comes out from internal. As the extrinsic and intrinsic motivation has known as the factors why people use electronic networking [12]. The sense of enjoyment in using a given system should also reduce anxiety and help people feel confident about their ability to successfully execute the requisite actions [15].

As enjoyment is one of the factor to see either it gives positive impact to the customer of e-travel website that will create satisfaction of the customer itself. Therefore, enjoyment reflects consumer's perceptions regarding to the potential entertainment of using internet service which is the e-travel website, as entertainment lead to the satisfaction of using it. Thus, enjoyment have significant influence towards the use and self-efficacy to the satisfaction of users that using e-travel website.

\section{Actual Use}

In this study, type of website considered by the researcher is e-travel website. It is defined as the actual action from individual to use a program. The use of e-travel website can be defined as the activity where users have decided to use the website and have some activities on it.

Many researcher have done research related with factors which influence people's use of website [15][16]. Davis asserts that one's behavioral intention influences actual system usage [17]. They have found some factors that influence the use of website such as: self-efficacy, enjoyment, perceived usefulness and etc. Based on the users' point of view, people tend to feel satisfied with the technology because of their behavioral intention that comes from enjoyment, self-efficacy and the use of website itself.

\section{E. Self-Efficacy}

According to Bandura's theory, people with high self-efficacy which is those who believe they can perform well and are more likely to view difficult tasks as something to be mastered rather than something to be avoided. People with high self-efficacy are more likely to use the electronic service that can be considered as crucial to the success of any electronic service [18]. Self-efficacy also is people's judgement of their capabilities to perform given task. It relates on the belief of each individual to perform a specific tasks. As social cognitive theory posits that people are neither driven by inner forces, nor simply by external stimuli. As the key of the activator in determine the human behavior is self-efficacy.

Computer self-efficacy is a skill that people have which shown by how much effort to invest, and how to face the challenge which appears [19]. Individuals with high self-efficacy had less resistance to change the technological innovations. As this is because consumers who possessed high perceived of self-efficacy are more likely to create positive perception about the use of technology. Thus, self-efficacy to computer technology has been found to exert a significant positive influence on affect (pleasure) and a significant negative influence on anxiety (dominance). More specifically, individuals with high self-efficacy tend to get more enjoyment and experience that is less anxiety in the adoption of new technology [20]. 
Self-efficacy play a critical role in self-motivation because it can influence decision about what behaviors to undertake and the amount of effort and persistance exhibited in attempting those behaviors [20]. Furthermore, they will be more confident if they consider themselves as having stronger capability of performing a specific online task [21].

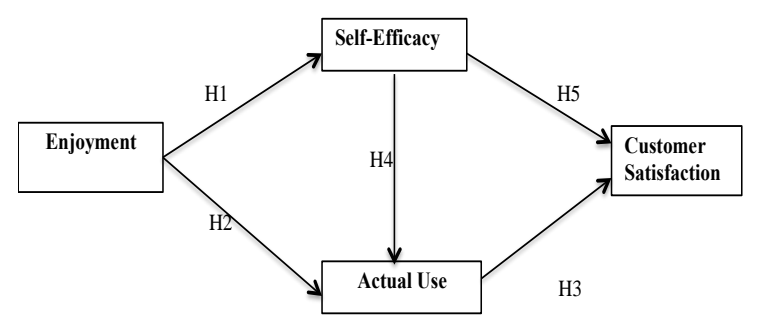

Fig. 1. Theoretical framework.

Then, before making any decision to purchase any product, users have to feel comfort and confident with the website hence, as their intention to use the website will become actual purchase [16]. This indicates that self-efficacy can be significant relevant to the satisfaction of users [22].

Finally, five hypothesis has been developed in this research:

H1: Enjoyment gives influence to the use of e-travel website

$H 2$ : The use of website gives influence towards the users satisfaction
H3: Enjoyment gives influence to the self-efficacy of e-travel website

H4: Self-efficacy gives influence to the use of e-travel website.

H5: Self-efficacy gives influence to the users satisfaction.

\section{RESEARCH METHODOLOGY}

This research used quantitative research model that will examine the relationship among the variables that are enjoyment, self-efficacy and actual use that influence the users satisfaction of using e-travel website. This quantitative research design had been selected in order to find out the appropriate answers to the research questions and to test the hypotheses [23].

Population refers to the entire group of people, events, or things of interest that the researcher wishes to investigate [15]. This research is to investigate the satisfaction of users in using e-travel website in Malaysia, as the population in this research is the students that is the internet users who have ever accessed the e-travel website in Malaysia.

This research use sample about 105 respondents. The data processing is using SmartPLS software (Partial Least Square) and a structural equation modeling (SEM) approach to develop a research model that represents the relationships among variables in this study: enjoyment, self-efficacy, actual use and satisfaction.

TABLE I: OUTER MODEL

\begin{tabular}{|c|c|c|c|c|c|c|}
\hline Item & Enjoyment & Self-efficacy & Satisfaction & Use & AVE & Composite reliability \\
\hline EY1 & 0.916230 & 0.679718 & 0.673267 & 0.667259 & & \\
\hline EY2 & 0.849347 & 0.713178 & 0.664260 & 0.635687 & & \\
\hline EY3 & 0.906052 & 0.709749 & 0.711537 & 0.658392 & 0.702573 & 0.920534 \\
\hline EY4 & 0.876316 & 0.627716 & 0.636426 & 0.510110 & & \\
\hline EY5 & 0.602609 & 0.443318 & 0.492680 & 0.301259 & & \\
\hline SE1 & 0.598194 & 0.825911 & 0.566687 & 0.663647 & & \\
\hline SE10 & 0.538150 & 0.720181 & 0.546266 & 0.503749 & & \\
\hline SE11 & 0.719578 & 0.829885 & 0.602692 & 0.642641 & & \\
\hline SE12 & 0.601328 & 0.793912 & 0.481065 & 0.626409 & & \\
\hline SE2 & 0.532175 & 0.784494 & 0.475533 & 0.554735 & 0.577506 & 0.937237 \\
\hline SE3 & 0.532091 & 0.774155 & 0.535180 & 0.550062 & & \\
\hline SE4 & 0.582707 & 0.810132 & 0.593740 & 0.525509 & & \\
\hline SE5 & 0.461353 & 0.702727 & 0.552329 & 0.525307 & & \\
\hline SE6 & 0.605693 & 0.785461 & 0.580837 & 0.631356 & & \\
\hline SE7 & 0.556376 & 0.629408 & 0.576729 & 0.515998 & & \\
\hline SE8 & 0.648004 & 0.674378 & 0.542942 & 0.525116 & & \\
\hline ST1 & 0.676940 & 0.589571 & 0.828239 & 0.520520 & & \\
\hline ST2 & 0.689560 & 0.654733 & 0.918913 & 0.594629 & 0.774151 & 0.911223 \\
\hline ST3 & 0.652571 & 0.669494 & 0.889985 & 0.616820 & & \\
\hline USE1 & 0.631470 & 0.738727 & 0.579578 & 0.816300 & & \\
\hline USE2 & 0.421030 & 0.452267 & 0.474647 & 0.706079 & 0.612158 & 0.862882 \\
\hline USE3 & 0.485639 & 0.528863 & 0.479955 & 0.813069 & & \\
\hline USE4 & 0.566440 & 0.591992 & 0.511026 & 0.789086 & & \\
\hline
\end{tabular}

EY=Enjoyment, SE=Self-Efficacy, ST=Satisfaction, USE=Actual Use 


\section{RESULTS}

The researcher gathered the data through online questionnaires, my3q website that will be processed and analyze. The respondents are the internet users who have accessed the travel website based in Malaysia. The 105 questionnaires are collected and be processed.

The researcher do is testing the validity of each variable employing SmartPLS 2.0. The validity of data is evaluated by validity test and convergent test that measured by the outer loading through algorithm process. Convergent validity is to examine whether the indicators of each variables definitely measure its variables. It also means convergent validity is measured based on correlation between score item and indicators (component score) with construct score. The indicators will state as valid if the value of outer loading more than 0.70 , but for loading 0.50-0.70 still can be accepted as long as value of AVE and communality more than 0.50 [24].

There is value of outer loading that is more than 0.5 will be deleted that shows the result more than 0.5 but less than 0.7 . The indicator is from self-efficacy (SE 9). The results data will be process using PLS software that provides outer loading value for indicator variables: Enjoyment, Self Efficacy, Actual Use of website and Customer Satisfaction. In order to continue the data processing, indicator SE 9 will be deleted since researcher used the AVE value more than 0.5 that is already fulfill the criteria of convergent validity test.

After deleting invalid indicator SE 9 and processed the data once more, the researcher got the new values of outer loading that are more than 0.5 and considered as valid data. The new outer loading values show the valid data that fulfill the rule of thumb criteria, more than 0.5 .

\section{A. Validity Test}

Discriminant validity is used to show that the construct or latent variables are predicted their own blocks size better than the other blocks size. In the discriminant validity, if the indicators correlation of constructs has a higher value than the other indicator correlation to the other constructs, the constructs will have high discriminant validity. All indicators also show that they have already had higher correlation to their own variables than to the other variables. Therefore, it already fulfilled the criteria. Table I shows all of the indicators that already have a higher correlation value to the variable that tested them than the other variables, it has already meet the validity of the discriminant.

The discriminant validity can be see through by comparing the root of AVE (Square Root of Average) that shows the construct must be higher than the correlation between latent variables [25]. Thus, it can be concluded that all of latent variables has a discriminant validity will be sufficient if the root of AVE for any invalid construct is larger than the correlation between invalid constructs. Cross loading and AVE are shows in Table II.

TABLE II: DISCRIMINANT VALIDITY FOR MEASUREMENT MODEL

\begin{tabular}{lcccc}
\hline \hline \multicolumn{1}{c}{ Constructs } & Enjoyment & Satisfaction & Self-efficacy & Use \\
\hline \hline Enjoyment & 0.838196 & & & \\
Satisfaction & 0.763544 & 0.879858 & & \\
Self-efficacy & 0.768524 & 0.726437 & 0.759938 & \\
Use & 0.683214 & 0.658077 & 0.753810 & 0.928914 \\
\hline \hline
\end{tabular}

Diagonal in parentheses Square root of average variance extracted from observed variables

\section{B. Reliability Test}

Reliability test is a test to examine the consistent over time by testing the accuracy and measurement precision of tool. In this research, it is also todetermined from the value of composite reliability for each block of indicators on reflective invalid constructs.

Rule of thumb of Cronbach's alpha and composite reliability must be higher than 0.7 and 0.6 value can be accepted [25]. The value of composite reliability shown in Table I.

\section{Structural Measurement}

Structural measurement shows in Table III and Appendix. From the observation, all of the hypothesis: $\mathrm{H} 1, \mathrm{H} 2, \mathrm{H} 3$, and $\mathrm{H} 4$, and $\mathrm{H} 5$ are supported (significant t-values).

The test relationships between constructs indicates the enjoyment gives influence to self-efficacy and actual use, self-efficacy influence actual use and actual use along with self-efficacy influence satisfaction of users in using tour and travel website in Malaysia with significances at 0.05 .

TABLE III: INNER MODEL AND HYPOTHESIS TESTING

\begin{tabular}{lll}
\hline \hline Hypothesis & Observed T-value & $\begin{array}{c}\text { Sig. Level } \\
\text { (1-tail) }\end{array}$ \\
\hline Enjoyment => Satisfaction & 9.196336 & Supported \\
Enjoyment $=>$ Self-efficacy & 16.79994 & Supported \\
Enjoyment => Use & 12.535220 & Supported \\
Self-efficacy => Satisfaction & 9.488113 & Supported \\
Self-efficacy => Use & 6.404482 & Supported \\
Use => Satisfaction & 2.538784 & Supported \\
\hline \hline
\end{tabular}

\section{CONCLUSION}

This study has examined the influence of perceived enjoyment, self-efficacy, and actual use of website towards the satisfaction of users in using tour and travel website in Malaysia. In this research, there are 105 respondents quesionnaires and using SEM/PLS. All of four hypothesis are significant influences. It gives meaning that perceived enjoyment gives impact to actual use of website and self-efficacy thus, actual use gives impact to the satisfaction of customer in using websites. By that, all of these factors gives impact of satisfaction to the users who used the travel website.

\section{APPENDIX}

\begin{tabular}{ll}
\hline \hline Item & \\
\hline ST1 & Satisfied \\
ST2 & Successful \\
ST3 & Expectations \\
EY1 & Fun \\
EY2 & Convenient \\
EY3 & Heartening to \\
EY4 & Very interesting \\
EY5 & A way to fill time \\
SE1 & Ability to use the e-travel website \\
SE2 & Skill to find information in the e-travel directory \\
SE3 & Know to fill up the online forms of the e-travel website \\
SE4 & Ability to communiacte \\
SE5 & Ability to download the file \\
SE6 & Ability to send email \\
SE7 & Ability to use favorites in the e-travel website \\
SE8 & Confident to use e-travel websites although no one teaches \\
SE9 & Confident to solve trouble shooting e-travel website problems \\
SE10 & Confident when using the e-travel website though never used \\
\hline \hline
\end{tabular}




\begin{tabular}{ll}
\hline SE11 & it before \\
SE12 & Having skills for using the e-travel website \\
USE1 & Information search \\
USE2 & Customer service request \\
USE3 & Purchase \\
USE4 & Payments \\
\hline \hline
\end{tabular}

\section{ACKNOWLEDGMENT}

The authors are grateful to Andalas University, Indonesia and Minister of Indonesian Higher Education (Dikti-DP2M) for giving the financial support of this research as International Research Collaboration grant and scientific Publication 2012 and 2013.

\section{REFERENCES}

[1] TM Net: Wikipedia. (February 2014). [Online]. Available: http://en.wikipedia.org/wiki/TMnet

[2] Z. B. M. Rani. "Assessing customer behavior towards tourism website in Malaysia," Master dissertation, Faculty of Hotel \& Tourism Management, University Technology Mara, 2009.

[3] A.-M. Khalid and A. Noor, "Service quality, ease of use, usability and enjoyment as antecedents of E-CRM performance: An empirical investigation in Jordan mobile phone services," The Asian Journal of Technology Management, vol. 2, no. 2, 2009.

[4] M. Lexhagen, Customer Perceived Value of Travel and Tourism Websites, European Tourism Research Institute, vol. 3, 2008.

[5] M. D. Norzaidi, S. C. Chong, R. Murali, and M. I. Salwani, "Internet usage and managers' performance in the port industry," Industrial Management \& Data Systems, vol. 107, no. 8, pp. 1227-1250, $2007 \mathrm{~b}$.

[6] B. Angelova and J. Zekiri, "Measuring customer satisfaction with service quality using American customer satisfaction model (ACSI model)," International Journal of Academic Research in Business and Social Sciences vol. 1, no. 3, 2011.

[7] I. Ajzen, The Theory of Planned Behavior. Organizational Behavior and Human Decision Processes, University of Massachusetts at Amherst, vol. 50, pp. 179-211, 1991.

[8] T. Van Vuuren, M. Roberts-Lombard, and E. Van Tonder, "Customer satisfaction, trust and commitment as predictors of customer loyalty," Southern African Business Review, vol. 16, no. 3, 2012.

[9] A.-K. M. Mufaddy, D. Subhasish, and A.-F. A. Hmoud, "Factors Affecting E-service Satisfaction," IBIMA Publishing, Communications of the IBIMA, 2011

[10] Z. Moshe, G. Chanan, and A. Itay. (2005). User Satisfaction from Commercial Web Sites: The effect of design and use. Information and Management. [Online]. Available: www.sciendirect.com

[11] M. P. Salami, "Impact on Customer Relationship Management (CRM) in the Iran Banking Sector," International Journal of Organizational Innovation, vol. 2, no.1, pp. 225-251, 2005.

[12] P. Kotler and K. L. Keller, Marketing Management, $14^{\text {th }}$ Edition. New Jersey, Prentice Hall, 2012, ch. 2, pp. 128-130.

[13] W. H. Delone and E. R. McLean, "Measuring e-commerce success: Applying the delone \& mclean information system success model," International Journal of Electronic Commerce, vol. 9, no. 1, pp. 31-41, 2004.

[14] C. Hart, A. M. Farrell, G. Satchow, G. Reed, and J. W. Cadogan. Shopping Experience Enjoyment: Impact on Customers' Repatronage Intentions and Gender Influence, 2006.
[15] T. S. H. Teo, "Demographic and motivation variables associated with internet usage activities," Internet Research: Electronic Networking Applications and Policy, 2001.

[16] Y.Mun Yi and Yujong Hwang (2003). Predicting the use of web-based information system: self-efficacy, enjoyment, learning goal orientation, and the technology acceptance model.International Journal of Human-ComputerStudies, pp. 431-449.

[17] . D. Davis, "Perceived usefulness, perceived ease of use, and user acceptance of information technology," MIS Quarterly, vol. 13, no. 3, pp. 319-340, 1989.

[18] N. Abd Aziz, G. Musa and A. Sulaiman, "The influence of predictors on travel web site adoption among Malaysian travelers," African Journal of Marketing Management, vol. 2, no. 6, pp. 107-122, 2010.

[19] Pajares (2002). Overview of social cognitive theory and of self-efficacy. [Online]. Available: http://www.emory.edu/EDUCATION/mfp/eff.html

[20] S. Kulviwat, G. C. Bruner II, and J. P. Neelankavil, The Role of Self-efficacy in Predicting Technology Acceptance, Academy of Marketing Science Conference, 2005.

[21] Y.-Y. Chen, H.-L. Huang, Y.-C. Hse, H.-C. Tseng, and Y.-C. Lee, "Confirmation of Expectations and Satisfaction with the Internet Shopping: The Role of Internet Self-efficacy," Computer and Information Science, vol. 3, no. 3, 2010.

[22] J. Y. Kim and H. S. Lee, "Key factors influencing customer satisfaction in Korea's mobile service sector," Journal of Internet Banking and Commerce, vol. 18, no. 3, 2013.

[23] U. Sekaran, Research Method for Business, $4^{\text {th }}$ ed. New York: John Wiley \& Sons, Inc, 2003.

[24] I. Ghozali, Structural Equation Modelling Metode Alternative with Partial Least Square (PLS), Semarang: Badan Penerbit Universitas Diponegoro, 2006.

[25] W. W. Chin and P. R. Newsted, "Structural equation modeling with small sample using Partial Least Square," in Statisticalstrategies for Small Sample Research, Thousands Oaks, R. Hoyle, Ed. CA: Sage Publications, 1999.

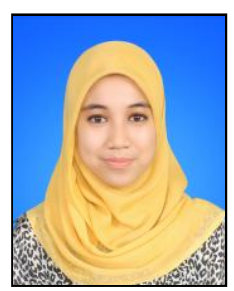

Puteri Fatin Nadia was born in Negeri Sembilan, Malaysia on September 17, 1992. Now she as a undergraduated student is in final year in University of Andalas, West Sumatra, Indonesia since 2010. Her major is in human resource management in the Management Department, International Program.

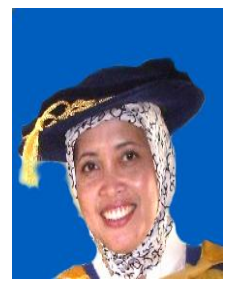

Vera Pujani is a senior lecturer in Economic Faculty, Andalas University. She finished her bachelor degree on management in Andalas University, Indonesia in 1993, she got the master degree at Management of Technology in Universiti Technologi Malaysia in 1997 and doctoral degree at e-commerce in Southern Cross University, Australia in 2008 